\title{
La rehabilitación del arco de Santa María como sede del Museo de Bellas Artes y Antigüedades de Burgos
}

\author{
Jesica SAN JUAN FEBRERO \\ Becaria de Investigación de la Junta de Castilla y León
}

\begin{abstract}
RESUMEN. El estudio monográfico de la primera sede del Museo de Burgos nos permite analizar el papel que tuvo la instalación de los museos provinciales en la recuperación del Patrimonio Monumental.

Palabras clave: Rehabilitación arquitectónica, Arco de Santa María, Museo de Bellas Artes y Antigüedades de Burgos.
\end{abstract}

RÉSUMÉ. L'étude monographique du premier siège du Musée de Burgos nous permet analyser l'importance de l'installation des musées provinciaux dans le domaine de la récupération du Patrimoine Monumental.

Mots clés: Réhabilitation architectonique, Arc de Sainte Marie, Musée de Beaux Arts et Antiquités de Burgos.

El convulso siglo XIX, marcado por los enfrentamientos bélicos y el proceso desamortizador, constituye uno de los momentos más decisivos en la degradación de nuestro patrimonio monumental. Su estado, a menudo ruinoso, había impulsado la aparición de un necesario interés por su defensa y conservación. A esa necesidad de protección de los inmuebles históricos se unió la falta de sedes que garantizaran la conservación de los bienes muebles también en manos del Estado. La unión de ambas exigencias desembocó, por fin, en una de las vertientes más fructíferas de la arqui- tectura de museos: la rehabilitación de edificios históricos con fines museísticos ${ }^{1}$.

Las Comisiones Provinciales de Monumentos, responsables de la instalación de las colecciones incautadas, se inclinaron, en la elección de sedes museísticas, por aquellos edificios de mayor prestancia arquitectónica, de carácter monumental y de cualidades histórico-artísticas que los convertían en verdaderos emblemas. La arquitectura constituía así un medio de legitimación para la nueva institución, nacida con

\footnotetext{
${ }^{1}$ Algunos autores defienden incluso que la instalación de los primeros museos constituye una excusa puesta al servicio del Monumento. C. BAZTÁN, «Museos en Monumentos. Una pequeña historia y 30 ideas», Revista de Museología, 13, 1999, pp. 25-31.
} 
vocación pública, mientras que ésta última fue entendida desde su origen como un medio de revitalización de los inmuebles desamortizados.

El proceso de formación e instalación de las colecciones burgalesas en el Arco de Santa María ilustran esta situación, extensible a todo el territorio nacional.

\section{CONTEXTO SOCIO-CULTURAL}

La situación económica y social de la ciudad burgalesa del siglo XIX era el producto de un periodo de revitalización vivido en todo el país tras las consecuencias de la Guerra de la Independencia².

El impulso que la industria y el comercio burgaleses habían recibido durante el segundo cuarto del siglo XIX tuvo importantes repercusiones sociales, principalmente en la aparición de una clase burguesa que exigía la creación de lugares destinados al ocio y la cultura. En este contexto, y como fruto de las desamortizaciones, fue fundado el primer museo público de la provincia. Por este motivo, la capital contaba con varias asociaciones de carácter lúdico en las que los miembros más acomodados de la clase media pasaban sus ratos de ocio. Tal era el caso del Liceo Artístico y Literario o el Círculo de Recreo, donde disponían de gabinetes de lectura, bibliotecas y mesas de billar. Como era habitual en todas las capitales de la provincia, Burgos contaba con la activa presencia de la Sociedad Económica, orientada a las "tareas patrióticas que tienen

\footnotetext{
2 A las tradicionales producciones agrícola -fundamentalmente de cereal- y ganadera, había que sumar la importancia de una incipiente industria, con especial desarrollo de la recién creada fábrica de papel. Con estas tres actividades, el comercio de Burgos estaba asegurado. En este sentido, fueron importantes las relaciones mantenidas con toda la costa cantábrica -Santander y País Vasco-, pero también con la capital y con Andalucía. P. MADOZ, Diccionario GeográficoEstadístico-Histórico de España y sus posesiones de ultramar, Madrid, 1847, p. 585.
}

por objeto el fomento de los intereses materiales de la provincia y la propagación de las luces de la misma" ${ }^{\prime \prime}$. Aunque entre ellas no se encontraba la colaboración con las Comisiones Provinciales de Monumentos en el proceso de formación del museo, estas asociaciones resultan interesantes como fruto del contexto regionalista de mediados del siglo XIX, impulsor de los museos provinciales.

\section{LAS PRIMERAS SEDES PROVISIONALES}

El hallazgo de una sede conveniente para la instalación de los objetos recuperados por la Comisión -mayoritariamente arqueológicos- constituyó una verdadera odisea que implicó no sólo los constantes traslados de las piezas, sino su almacenamiento simultáneo en varios locales, con una consecuente dispersión en absoluto beneficiosa para su conservación. En estas circunstancias, el establecimiento de la sede del museo debió plantearse como un medio para garantizar el correcto estado de conservación de las obras.

No existen muchas noticias sobre la Comisión de Monumentos de Burgos. Sin embargo, y a juzgar por los resultados, debió contar con un equipo implicado y activo. Se tienen noticias de que, en una fecha tan temprana como 1842 -por tanto, como fruto de los trabajos de la todavía Comisión Científica y Artística-, los objetos incautados "se encerraron provisionalmente en el colegio de San Nicolás y en el colegio de San Pablo de esta capital, quedando otros varios dispersos en otros conventos de la provincia", además de alojarse gran parte de los mismos en el Seminario Conciliar de San Jerónimo, sucios y en condiciones de almacenaje, por lo que no constituían sedes museísticas propiamente dichas ${ }^{4}$.

\footnotetext{
3 Ibídem, p. 544.

${ }^{4}$ Real Academia de Bellas Artes de San Fernando (en adelante R.A.B.A.S.F.), Comisión Provincial de Mo-
} 
Durante la estancia de los fondos del museo en San Jerónimo, el seminario continuaba con el normal desempeño de sus funciones, circunstancia que obligó a mantener las piezas amontonadas en locales poco convenientes para su correcta conservación. Por este motivo, en 1847, la Comisión Central de Madrid inició una serie de trámites para la cesión de algún otro edificio en el que poder instalar esta nueva institución de manera definitiva. En este sentido, y dada la enorme cantidad de edificios religiosos que tras la desamortización habían quedado inhabilitados, las distintas propuestas presentadas por las comisiones -central y provincial- fueron orientadas a la cesión de alguna iglesia o convento en desuso.

Las pésimas condiciones en las que se encontraban las piezas en los locales de San Jerónimo, unido al considerable aumento del alumnado y la consiguiente necesidad de más espacio destinado a los estudiantes, llevaron a la central a solicitar la iglesia de San Pablo para, si fuese posible, instalar en ella el museo ${ }^{5}$. Finalmente, el citado inmueble no fue cedido, por lo que se inició toda una serie de solicitudes cuya concesión ocasionó el constante traslado de los fondos del museo.

Durante el periodo que va desde 1849 a 1870, el grueso de las colecciones estuvo instalado en numerosos inmuebles, la mayoría de carácter religioso, sedes que no constituyeron más que almacenes para las piezas. No existían, por tanto, pretensiones expositivas o de apertura al público,

numentos de Burgos (1835-1872), Sig. 46-7/2, Carta de la Comisión Provincial de Monumentos de Burgos dirigida al Excmo. Señor Secretario de Estado y del Despacho de la Gobernación de la península, y fechada en Burgos el 6 de agosto de 1842.

5 Archivo Municipal de Burgos (en adelante A.M.B.), carpeta 1847, documentación diversa. Dato consultado en B. CASTILlO y M. NEGRO, 150 años del museo de Burgos, Burgos, 1996, p. 17. y las piezas no se disponían en el espacio siguiendo criterios de ordenación museológica determinados ${ }^{6}$.

En esta lamentable situación llegaron las piezas al año 1870 cuando, actuando la Diputación como intermediaria entre la Comisión Provincial de Monumentos y las autoridades eclesiásticas competentes, se concedió como sede el conocido como Convento de las Trinas ${ }^{7}$. El edificio había sido, como no podía ser de otra manera, una de las víctimas del proceso desamortizador. Tras ser demolido el inmueble original para ejecutar una importante renovación urbanística, las religiosas habían conseguido los recursos necesarios para reconstruir el convento que desde 1870 dio cobijo al Museo de Burgos. La fábrica, de mampostería, evidenciaba los escasos fondos con los que se había llevado a cabo la obra así como su

\footnotetext{
${ }^{6}$ No obstante, y como testimonio de las penurias sufridas por los comisionados, haré una breve referencia a los hechos acaecidos durante el periodo señalado. Tras la denegación de la solicitud de San Pablo como sede para el museo, el jefe político solventó el problema de la comisión con la concesión, el 31 de diciembre de 1849, de otro colegio, esta vez el de San Nicolás, en el que se instalaron las piezas. A pesar de las buenas condiciones en las que se encontraba el inmueble, fue de nuevo el incremento del alumnado el que generó problemas de espacio, obligando a amontonar las piezas y causando graves problemas de conservación, sobre todo en las obras pictóricas. La dificultad para encontrar una nueva sede por el escaso entendimiento entre la comisión y el arzobispado, ocasionó la dispersión de los fondos en tres inmuebles diferentes. Así, entre 1865 y 1870, el colegio de San Nicolás mantuvo la custodia de las pinturas, mientras que el colegio de sordomudos y ciegos almacenaba en sus locales aquellas piezas más voluminosas y pesadas. El tercer inmueble, que había sido cedido por la Diputación en 1866, era un edificio civil, el Consulado del Mar, donde se recogían los objetos más pequeños: el gabinete numismático, los libros y los documentos recogidos en conventos desamortizados. B. CASTILlO y M. NeGRO, 150 años del museo..., pp. 18-22.

${ }^{7}$ La petición fue aprobada el 11 de febrero de 1870. Ibídem.
} 
pobreza y simplicidad desde el punto de vista arquitectónico ${ }^{8}$.

Incluso la propia Comisión había admitido el escaso valor histórico, arquitectónico y artístico del inmueble, mostrando con ello cierta decepción al no tratarse de un edificio solemne y monumental, presente en la memoria de todos los burgaleses, según marcaban los cánones del momento con respecto a las sedes museísticas. Así, decían:

"Construido este convento con bien escasos recursos después del año 1830, ni conserva recuerdo histórico alguno, ni en él se encuentran miembros ni objeto alguno de arte que merezca conservarse" $^{\prime \prime}$.

Ante la pronta instalación de las piezas del museo en el edificio, la comisión encargó a uno de sus miembros, el vocal y arquitecto D. Luis Villanueva, la elaboración de un presupuesto de obras para reformar el convento y adaptar sus dependencias a las nuevas funciones. Aunque el primer presupuesto no fue aprobado por la Diputación -ni qué decir tiene, por razones económicas-, finalmente se llevaron a cabo pequeñas obras de consolidación cuyo coste alcanzó las 1.900 pesetas ${ }^{10}$. La intención, por tanto, había sido buena al pretender llevar a cabo obras de rehabilitación para la adecuación de las salas a su nueva función expositiva. Sin embargo, una vez más fue el factor económico el que había frenado las miras de los comisionados.

El Museo de Burgos, con el nombre de Museo de Bellas Artes y Antigüedades,

\footnotetext{
${ }^{8}$ L. S. IGLESIAS ROUCO, Burgos en el siglo XIX. Arquitectura y urbanismo (1813-1900), Valladolid, 1979, p. 109.

${ }^{9}$ A.M.B., carpeta 1870. Es un texto fechado el 5 de octubre de 1870. B. CASTILlO y M. NEGRO, 150 años del museo..., pp. 23-36.

${ }^{10}$ B. CAstillo y M. Negro, 150 años del museo..., p. 20
}

fue finalmente inaugurado el 14 de septiembre de 1871.

El convento, proyectado por el mismo arquitecto que se había ocupado posteriormente de su rehabilitación -Luis Villanueva-, tenía planta rectangular, muy senci1la. La iglesia, que se levantaba en el centro del conjunto, se remataba con una cúpula con linterna, elementos que constituían el único guiño a la monumentalidad de todo el conjunto. Alrededor de la iglesia se distribuían todas las dependencias, antaño conventuales, pero transformadas ahora para albergar en ellas las colecciones artísticas de la provincia ${ }^{11}$. Desconocemos, en este sentido, cuál era la distribución de los objetos en su interior. Sin embargo, poco duró el establecimiento del museo en la que había sido su primera sede. La inauguración oficial de la institución no impidió que su escaso peso real en la ciudad, unido al poder de la iglesia, provocaran de nuevo el traslado hacia otra sede en la que permanecería cerca de 80 años.

El problema surgió el 30 de diciembre de 1874, cuando la Diputación de Burgos acordó devolver a las religiosas el antiguo convento. La instalación de las monjas en sus antiguas dependencias no causó, sin embargo, el inmediato traslado de los fondos del museo debido a la resistencia de los comisionados, que llegaron a elevar sus protestas a la corona. Durante los dos años que duraron los litigios, las dos instituciones -Iglesia y Comisión- compartieron sede, hasta que en julio de 1877 el Ministerio de Hacienda cedió definitivamente a las religiosas los derechos sobre el inmueble ${ }^{12}$. En aquel momento, las piezas más pesadas se repartieron, en calidad de depósito, entre el convento de las Trinas y el Colegio de sordomudos y ciegos. El Consulado del

\footnotetext{
${ }^{11}$ Ibídem, pp. 23-36.

${ }^{12}$ Ibídem, p. 21.
} 
Mar volvió a acoger los objetos más pequeños -numismática y las obras más valiosas-, mientras que en la sede de la diputación se custodiaron la mayor parte de las pinturas $^{13}$.

\section{LA RECUPERACIÓN DEL ARCO DE SANTA MARÍA}

En 1876 la Comisión Provincial de Monumentos de Burgos, en cumplimiento de sus labores, propuso la reconstrucción de los arcos de Santa María y San Esteban de la capital al Ayuntamiento ${ }^{14}$. Para la ejecución de las obras, que enseguida contaron con el beneplácito de la Corporación Municipal, se nombraron inspectores a D. Luis Villanueva y D. Ángel Calleja, vocales de la Comisión Provincial de Burgos y arquitectos de la Real Academia de Bellas Artes de San Fernando ${ }^{15}$. Tras llevar a cabo las primeras intervenciones en el Arco de Santa María, que afectaron a la parte exterior y al primer piso del interior, surgió la idea de la instalación en el edificio de las colecciones del ya constituido Museo de Burgos. La posibilidad de que uno de los edificios más señeros de la capital burgalesa se convirtiera en sede del recién constituido museo fue aceptada con agrado por todas las instituciones -Comisión, Diputación, Ayuntamiento- que comprendieron este intento como medio para revitalizar un edificio totalmente abandonado. En la Me-

\section{Ibídem.}

${ }^{14}$ R.A.B.A.S.F., Comisión Provincial de Monumentos de Burgos (1880-1911), Sig. 50-3/4, Memoria de la instalación del Museo Provincial firmada en Burgos el 7 de abril de 1880 por el conservador D. Juan Miguel Sánchez de la Campa y dirigida a la Real Academia de Bellas Artes de San Fernando, fol. 3 r y v. B. Castillo y M. Negro, por el contrario, aseguran que fue el Ayuntamiento de la capital el que tomó la iniciativa para la ejecución de las labores de limpieza en el Arco de Santa María. Ibídem, p. 22.

${ }^{15}$ R.A.B.A.S.F., Comisión Provincial de Monumentos de Burgos (1880-1911), Sig. 50-3/4, Memoria de la instalación del Museo Provincial firmada en Burgos..., fol. 3 $\mathrm{v}$. moria de instalación del Museo de Burgos, la comisión recogía lo siguiente:

"La Diputación de la Provincia que deseaba la reconstrucción de un establecimiento $\mathrm{cu}$ ya desaparición no habría visto con gusto, no desoyó las indicaciones que se hacían sobre la posibilidad de establecer el Museo Histórico y Artístico, en la antigua Torre de Santa María.

Ybase formando la opinión y el Excmo Ayuntamiento, no sólo no la rechazaba, sino que aparecía la posibilidad de que, la aceptara gustoso"16.

El Museo de Burgos se convirtió en agente revitalizador de un patrimonio monumental que amenazaba ruina, la torre de Santa María, en la que, a la indudable prestancia arquitectónica del inmueble, había que sumar la carga simbólica de sus elementos decorativos, convirtiéndolo en el perfecto contenedor para la nueva institución artística. El museo, concebido todavía como un cúmulo de objetos recopilatorios y representativos de la historia de la ciudad burgalesa, encontraba en su arquitectura un equivalente simbólico, tanto por la historia del propio inmueble como por la iconografía representada en su fachada y a la que posteriormente haré breve mención.

Ante las dudas planteadas acerca de la capacidad del inmueble para albergar el museo, la Comisión Provincial de Burgos ordenó a dos de sus vocales el reconocimiento del interior del edificio para emitir su opinión al respecto ${ }^{17}$. El conservador del Museo de Burgos, D. Juan Miguel Sánchez de la Campa, manifestaba sus principales preocupaciones, reflejo de los inconvenientes a los que a menudo solían enfrentarse los miembros de todas las comisiones provinciales de monumentos. La falta de espacio, y la consiguiente dispersión de las co-

${ }^{16}$ Ibídem, fol. 6 v.
${ }^{17}$ D. Juan Miguel Sánchez de la Campa y D. Manuel Villanueva fueron elegidos para el desempeño de esta función. Ibídem. 
lecciones, la cesión del inmueble por parte de las instituciones pertinentes, así como los fondos con los que hacer frente a las profundas obras de restauración requeridas por la futura sede fueron algunos de los asuntos a los que el conservador burgalés hacía referencia en la mencionada memoria $^{18}$.

Tras el visto bueno de los inspectores designados, Comisión y Ayuntamiento llegaron a un acuerdo por el cual la institución municipal cedía el inmueble como sede de museos, siempre y cuando la Comisión de Monumentos se comprometiera a conservar el edificio y a costear los gastos de rehabilitación, "dando así a este monumento un destino digno y asegurando por mucho tiempo su buena conservación" ${ }^{19}$. Este testimonio de la propia Comisión de Monumentos ponía de manifiesto el despertar de una conciencia de protección del patrimonio con la inmediata puesta en funcionamiento de medidas de conservación, entre las cuales se encontraba la reutilización del inmueble para usos renovados. Este interés por mantener en auge el patrimonio mo-

18 “Un obstáculo empero se destacaba. ¿Cabría en la torre el Museo? ¿Sería posible su establecimiento en ella? [...] ¿De dónde saldrían los fondos para las grandes obras que la realización de este proyecto exigía?". Ibídem.

${ }^{19}$ A.M.B., carpeta 1878. Memoria de obras realizada por el arquitecto y miembro de la comisión, D. Luis Villanueva, el 18 de enero de 1878. B. CASTILLO y M. NEGRO, 150 años del museo..., p. 22. En este punto no debemos olvidar que las Comisiones de Monumentos carecían de todo tipo de ingresos y que todos los gastos generados por el desempeño de sus funciones debían ser considerados en los presupuestos anuales de las respectivas Diputaciones Provinciales. No fue una excepción el caso de la recuperación del Arco de Santa María de Burgos para el que la Diputación burgalesa concedió "de su presupuesto ordinario dos mil pesetas y otras dos mil en el extraordinario [...] y consumidos los fondos consignados para ellas la Diputación provincial facilitó otros más en sus presupuestos ordinario y extraordinario". R.A.B.A.S.F., Comisión Provincial de Monumentos de Burgos (1880-1911), Sig. 50-3/4, Memoria de la instalación del Museo provincial firmada en Burgos..., fol. $7 \mathrm{v}$. numental de la ciudad se inscribía dentro del contexto del regionalismo y el pensamiento historicista tan decisivos en el proceso de formación de los museos provinciales.

Aunque proyectadas con anterioridad, las obras dieron comienzo cuando el inmueble ya había sido destinado para su nuevo uso como contenedor artístico, en torno a $1877^{20}$. Parece ser que el inicio de las intervenciones no fue demasiado fácil. En ese momento, el inmueble estaba ocupado por varias tiendas de ropa y vino adosadas en los bajos además de servir de residencia a los dependientes de dichos comercios, de manera que el Ayuntamiento, como propietario del edificio, tuvo que proceder a su desalojo y a la posterior reubicación de los vecinos allí hospedados. La documentación habla del "derribo de las tiendas de entramado que estaban adosadas a sus paredes [...]", por lo que debemos suponer que la intervención en el inmueble supuso la recuperación de la antigua distribución espacial del edificio que respondía a su uso como ayuntamiento "muy desde el principio [...], y especialmente desde el siglo XIV ${ }^{\prime 21}$. Contaba por tanto con sala de sesiones, oratorio, archivo, tesorería y demás dependencias destinadas al desempeño de sus funciones como casa del consejo. A la recuperación de los espacios primitivos se unió el empleo de materiales similares a los originales en un intento de recomponer el aspecto que originalmente había presentado el inmueble ${ }^{22}$.

-

20 "Hecha entrega por el Exmo. Ayuntamiento a la Comisión de Monumentos del edificio procedió esta á la ejecución de las obras". R.A.B.A.S.F., Comisión Provincial de Monumentos de Burgos (1880-1911), Sig. 50-3/4, Memoria de la instalación del Museo provincial firmada en Burgos..., fol. $7 \mathrm{v}-8 \mathrm{r}$.

${ }^{21}$ Ibídem, fol. $4 \mathrm{v}$.

22 "Todos cuantos han visitado á Burgos por espacio de muchos años, han fijado la atención en este edificio, pero muy pocos han subido su oscura escalera y recorrido su interior y era natural, distribuido en muchas y pequeñas 


\section{LA DISTRIBUCIÓN DEL ESPACIO EXPO- SITIVO}

La intervención en el edificio, que afectó fundamentalmente al interior de la torre, tuvo como principal repercusión la recuperación de su distribución espacial original, es decir, la sustitución de los espacios reducidos, oscuros y poco higiénicos por los salones diáfanos y las galerías amplias y abiertas al exterior, además de poner énfasis en aquellos elementos constructivos de valor artístico, como los arcos mudéjares de la entrada o el artesonado de la sala principal del recinto. De manera que cuando el museo se abrió al público por primera vez en su nueva sede, el 29 de junio de 1879, el interior había quedado organizado de la forma que a continuación se especifica (Lám. 2).

El acceso al museo se hacía por una puerta abierta en arco de medio punto y situada bajo la fachada de la torre que da al Arlanzón. A través del mencionado arco se accedía al vestíbulo de entrada denominado sala primera del museo. La planta de esta dependencia, rectangular aunque ocupada en sus extremos por la escalera monumental de acceso al piso superior, permitió en ella la exposición de piezas de gran envergadura, a saber, tres grandes sepulcros, varios escudos de armas, cuadros de grandes dimensiones y otros objetos variados que recibían una importante cantidad de luz procedente, por un lado, de tres grandes ventanales situados en uno de los muros de la sala, y por otro, de una apertura en el techo, combinando así los dos tipos de

habitaciones, y abandonado en otros puntos y ocupado en algunos por objetos inútiles, ni era posible apreciar la forma y circunstancias ni de su techo piramidal de ensambladura de la antigua Sala Municipal, ni sus deterioradisimas pinturas murales ni un notable arco mudéjar de dos huecos que había dado entrada a un extenso salón recortado luego en muchos puntos y transformado luego en sucio y abandonado desván, ni su triple ni amplísima galería ni nada en fin de cuanto la constituía". Ibídem, fol. $5 \mathrm{v}$. iluminación básicos en las primeras salas expositivas -lateral y cenital-.

Dos arcos mudéjares adosados a uno de sus muros -y considerados por los comisionados como elementos integrantes de la colección del museo- permitían la entrada a la habitación central, de planta cuadrangular e iluminada por una lucerna central, considerada la sala segunda del museo ${ }^{23}$. Albergaba ésta un sepulcro en el centro y cuadros de diversos tamaños repartidos por toda la estancia (Lám. 3).

En torno a la sala central se disponía una galería abierta mediante arcos a la fachada de la torre que da hacia la Plaza del Arzobispo. La estructura de este espacio responde a la tipología arquitectónica de las loggias italianas, uno de los espacios más perdurables a lo largo de la tradición expositiva $^{24}$. La galería, abierta al paisaje urbano, se convirtió en la sala expositiva de aquellas piezas más resistentes a las inclemencias del tiempo, la misma finalidad que recibieron los claustros procesionales de conventos y monasterios, convertidos en sedes de nuestros primeros museos ${ }^{25}$.

\section{-}

${ }^{23}$ Los arcos, respetados a lo largo de los siglos, fueron recuperados y realzados en el nuevo establecimiento como "uno de los notables objetos que en aquel museo figuraban". Ibídem, fol. 6 r. Los arcos mudéjares fueron asumidos como objetos expositivos, estrechando así los lazos entre contenedor y contenido y elevando el Arco de Santa María a la condición de pieza coleccionable.

${ }^{24}$ La galería tiene su origen en las loggias de los palacios mediterráneos, abiertas al paisaje contribuyendo así a su utilización como lugares de ocio y de esparcimiento. A esta tradición arquitectónica se sumó la costumbre francesa de decorar estas estancias palaciegas con los objetos procedentes de las colecciones particulares. J. C. RICO, Museos, Arquitectura, Arte. Los espacios expositivos, Madrid, 1994, p. 42.

${ }^{25}$ La documentación cita, entre los objetos de la colección ubicados en este espacio, esculturas de piedra -medallones, sepulcros, lápidas-, restos arquitectónicos -capiteles, arcos-, piezas metálicas -un frontal de bronce-, etcétera. R.A.B.A.S.F., Comisión Provincial de Monumentos de Burgos (1880-1911), Sig. 50- 
Desde el salón central, en la parte izquierda, una puerta daba acceso al que fue salón de reunión del consejo municipal y que tanto funcional como arquitectónica y estilísticamente hablando puede ser considerada la principal estancia del conjunto. Como tal, su organización espacial no es del todo convencional. Se trata de una estructura de planta octogonal cubierta con un imponente artesonado de madera ricamente decorado, respetado durante las reformas que sufrió la torre tras ser derribada parcialmente en el siglo XVI por el desbordamiento del Arlanzón (Lám. 4) ${ }^{26}$. La ausencia de problemas estructurales en esta dependencia permitió a los comisionados instalar en ella algunas piezas -dos cuadros de gran envergadura y nueve diplomas- sin necesidad de intervenir en ella. Sin embargo, el conservador del museo aseguraba en 1880 que "el interior de esta sala exige larga, costosa y minuciosa restauración", por lo que podemos suponer que ésta afectaría más a los elementos superfluos y decorativos de la estancia $-\mathrm{y}$ no a los constructivos-, no ejecutados en ese momento por falta de fondos ${ }^{27}$.

Analizadas ya las estancias del piso inferior, sólo resta aludir a la distribución de la segunda planta, mucho más sencilla al compartir espacios con la planta de entrada. A la galería inferior le correspondía otro piso de arcadas en la parte superior, no empleadas en este caso como salas longitudinales sino divididas en tres salas expositivas para la exhibición de las piezas menos

3/4, Memoria de la instalación del Museo provincial firmada en Burgos..., fol. 9 v-10 r.

26 "Sala que está cubierta por un techo piramidal fabricado de ensambladura y pintado al estilo mudéjar, y en cuya época debieron hacérsele algunas reparaciones y repintar parte de él, reparaciones y retoques que se observan aún hoy después de los años transcurridos". Ibídem, fol. 5 r-5 v. Al igual que los arcos anteriormente citados, el artesonado de la antigua sala del consejo constituía una pieza más de la colección.

${ }^{27}$ Ibídem, fol. $10 \mathrm{v}$. pesadas de la colección -restos de artesonado, el gabinete de numismática, la colección fotográfica de M. Laurent, etcéteraademás de reservar una pequeña sala como despacho del conservador, único espacio destinado a las labores de gestión del museo.

Aunque la tipología arquitectónica del edificio en el que se asentó el museo puede resultar novedosa-de carácter civil y propiedad del consejo municipal, y no uno de los resultantes del proceso desamortizador- lo cierto es que la distribución espacial no difiere en exceso de los ejemplos instalados en otro tipo de inmuebles, fundamentalmente de carácter religioso. La sala central, abierta cenitalmente y rodeada de una galería de arcos hace aquí las veces de patio distribuidor del espacio, mientras que las estancias expositivas se reducen a la tradición del gabinete y la galería, herederos de los palacios renacentistas y barrocos (Lám. $5)^{28}$.

\section{LA PRÁCTICA MUSEOGRÁFICA}

Desde el punto de vista museográfico, ya se ha apuntado que la exposición de las colecciones burgalesas combinaba la iluminación cenital con la lateral, mientras que la ordenación de las piezas, como era tradicional, seguía criterios cronológicos ${ }^{29}$.

\footnotetext{
${ }^{28}$ Como ya se ha apuntado, las loggias constituyen el antecedente de las galerías como espacios expositivos. Por otro lado, los gabinetes barrocos, procedentes de los studioli desarrollados principalmente en el marco del Renacimiento italiano, constituían espacios arquitectónicos de gran simplicidad. De manera que en cualquier sala expositiva podemos encontrar reminiscencias de estos primitivos espacios de exhibición científica y artística.

29 "En la galería que rodea este salón se hallan multitud de objetos de escultura, lápidas, sepulcros, capiteles, medallones y estatuas colocadas en orden cronológico". R.A.B.A.S.F., Comisión Provincial de Monumentos de Burgos (1880-1911), Sig. 50-3/4, Memoria de la instalación del museo provincial firmada en Burgos..., fol. 9 $\mathrm{v}-10 \mathrm{r}$.
} 
Se atendía con ello al concepto decimonónico de la historia, definida por Pi y Maragall como "una sucesión no interrumpida de causas y efectos" $"$ "

Con respecto al mobiliario expositivo, la documentación es parca y poco detallada. Sí recoge, por ejemplo, que los objetos más pequeños de la colección se custodiaban "en una gran mesa aparador de cristales" destinada a la colección de numismática, mientras que "dos armarios acristalados" servían a la exposición de esculturas de pequeño tamaño, mosaicos, fragmentos de armadura, etcétera ${ }^{31}$.

\section{EL VALOR SIMBÓLICO DE LA ARQUI- TECTURA}

Aunque la puerta de la muralla se abrió ya en época de Alfonso XI, el aspecto monumental que entonces se contemplaba, y que se ha mantenido en nuestros días, respondía a la reforma que la fachada experimentó a principios del siglo XVI, tras el derrumbe de parte de la estructura por el desbordamiento del Arlanzón. Para tal reforma se siguieron las trazas de un autor anónimo, aunque con modificaciones de dos artistas de renombre, Cristóbal de Andino y Felipe Vigarny, encargados de dotar de monumentalidad el exterior del edificio con el pretexto de conmemorar una visita reciente del emperador Carlos I a la ciudad burgalesa $^{32}$.

30 F. PI Y MARAGALL, Estudios sobre la Edad Media, Madrid, 1873, pp. 6-7. Dato consultado en J. L. ABELLÁN, Historia Crítica del Pensamiento Español. Liberalismo y Romanticismo (1808-1874), tomo IV, Madrid, 1984, p. 593

${ }^{31}$ R.A.B.A.S.F., Comisión Provincial de Monumentos de Burgos (1880-1911), Sig. 50-3/4, Memoria de la instalación del museo provincial firmada en Burgos..., fol. $10 \mathrm{v}-11 \mathrm{r}$

${ }^{32}$ I. GONZÁlEZ DE SANTIAGO, "El arco de Santa María en Burgos", Boletín del Seminario de Estudios de Arte y Arqueología, tomo LV, Valladolid, 1989, p. 293.
El Arco de Santa María constituía uno de los accesos a la ciudad a través de la vía que comunicaba Burgos con Valladolid y Madrid -una de las entradas más transitadas por razones comerciales- y uno de los edificios de mayor proyección social por su función como sede del ayuntamiento y como lugar donde tradicionalmente se había impartido justicia. Su origen conmemorativo explica la decoración de su fachada, con la representación escultórica del emperador en el centro como protector de la ciudad, con la intervención divina de Santa María y el ángel custodio y entroncando su estirpe con Fernán González y El Cid, entre otros personajes históricos burgaleses (Lám. $1)^{33}$.

Desde finales del siglo XVIII, el estado de las murallas de la ciudad era ruinoso. Incluso, de algunas de ellas se había aconsejado su desmonte a fin de evitar males mayores. La puerta, como ya se ha señalado, había sido utilizada hasta entonces como sede del consistorio, hasta que la construcción de un nuevo inmueble para estos fines, y posteriormente la invasión francesa, obligaron al desalojo del edificio. Con la Guerra de la Independencia tanto las murallas como sus puertas recuperaron el sentido y la funcionalidad con las que habían sido levantadas originalmente, comenzan-

\footnotetext{
${ }^{33}$ Las esculturas, de Ochoa de Arteaga, fueron colocadas en las hornacinas en 1533. Ibídem. "El arco moderno tiene basamento sobre el que descargan los capiteles: Tres zonas de estatuas sobre las que corre un orden [...]. Las estatuas que decoran las zonas son bustos que representan a Rodrigo Díaz de Vivar, a Laín Calvo y Nuño Rasura, jueces de Castilla, a Diego Porcelo fundador de Burgos, Fernán González conde independiente, Carlos I, Nuestra Señora y Ángel Custodio. Heraldos armados de mazas que contienen las armas de la ciudad y mil adornos grotescos completan la decoración". R.A.B.A.S.F., Comisión Provincial de Monumentos de Burgos (1835-1872), Sig. 46-7/2, Carta de la Comisión Provincial de Monumentos de Burgos dirigida al Excmo. Señor Secretario de Estado y del Despacho de la Gobernación de la península, y fechada en Burgos el 6 de agosto de 1842.
} 
do así una política de conservación y consolidación de las mismas ${ }^{34}$.

Quizá más importante que la organización interna del espacio sea, en el caso de Burgos, la reutilización de un edificio representativo de la ciudad como sede de la nueva institución museística. El Arco de Santa María, monumental y solemne, constituía por su decoración, su ubicación urbanística y su significación histórica, un compendio de los episodios más destacados en el desarrollo histórico de la ciudad, presentes en la memoria de todos los burgaleses. De acuerdo con el pensamiento romántico -que en su vertiente política supuso la aparición de los movimientos nacionalistas y regionalistas-, la sede del museo debía convertirse en reflejo de la riqueza y el grado de progreso de la nación. En esta idea reside el auténtico valor simbólico de la arquitectura del museo como institución que sintetiza, ejemplifica y transmite los valores de cada periodo histórico, recopilando los de épocas pasadas y perpetuándolos para las generaciones futuras ${ }^{35}$.

Con la instalación del museo provincial en este inmueble se establecía un fuerte vínculo simbólico entre continente y contenido, que convirtieron a la sede del museo de Burgos en una de las mejores definiciones de la institución en el siglo XIX español.

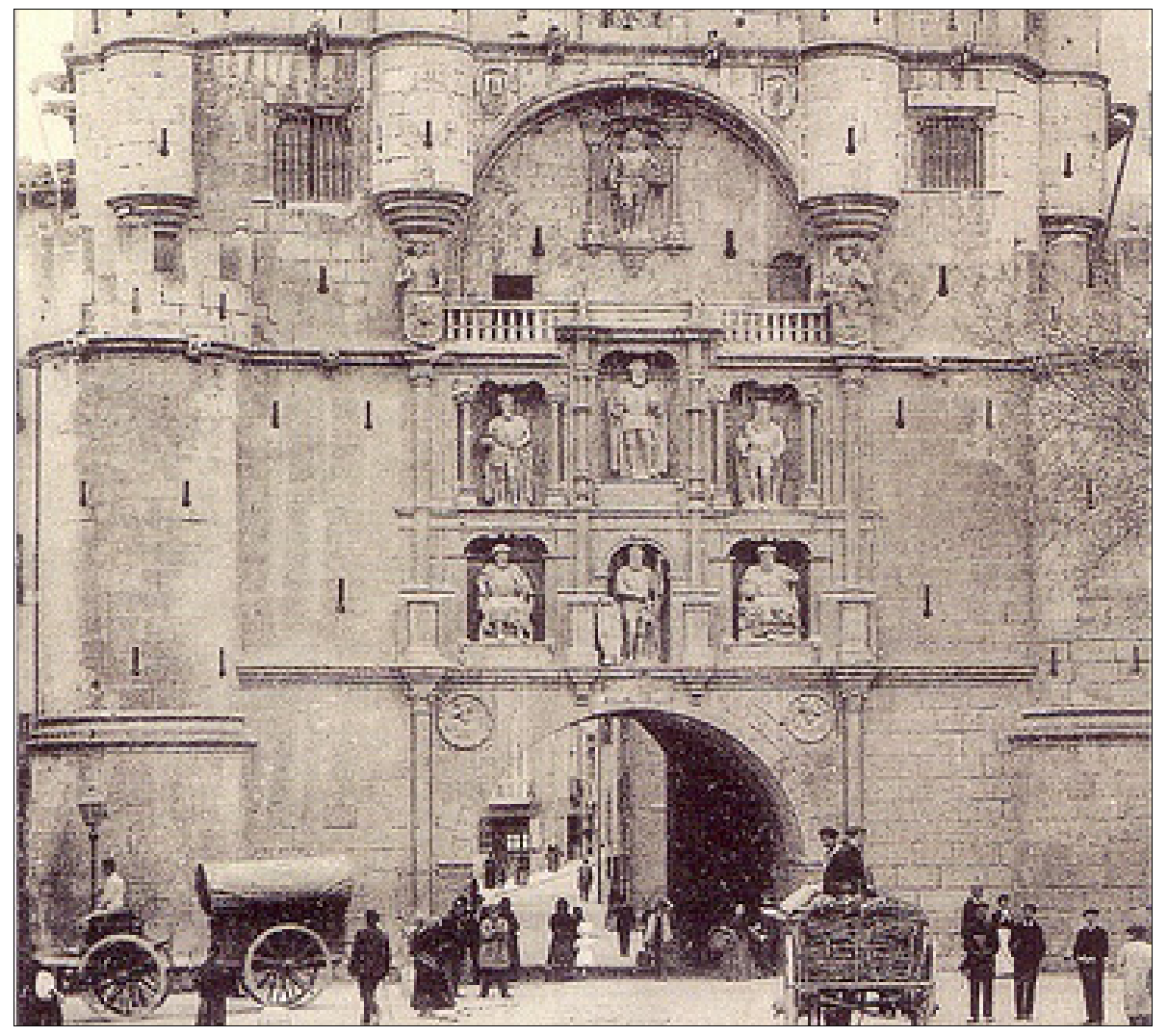

- Lám. 1. Fachada del Arco de Santa María.

${ }^{34}$ L. S. IGLESIAS ROUCO, Arquitectura y urbanismo de Burgos bajo el reformismo ilustrado (1747-1813), Burgos, 1978, p. 41.
${ }^{35}$ J. M. MONTANER y J. Oliveras, Museos para el siglo XXI, Barcelona, 2000, pp. 8-9. 


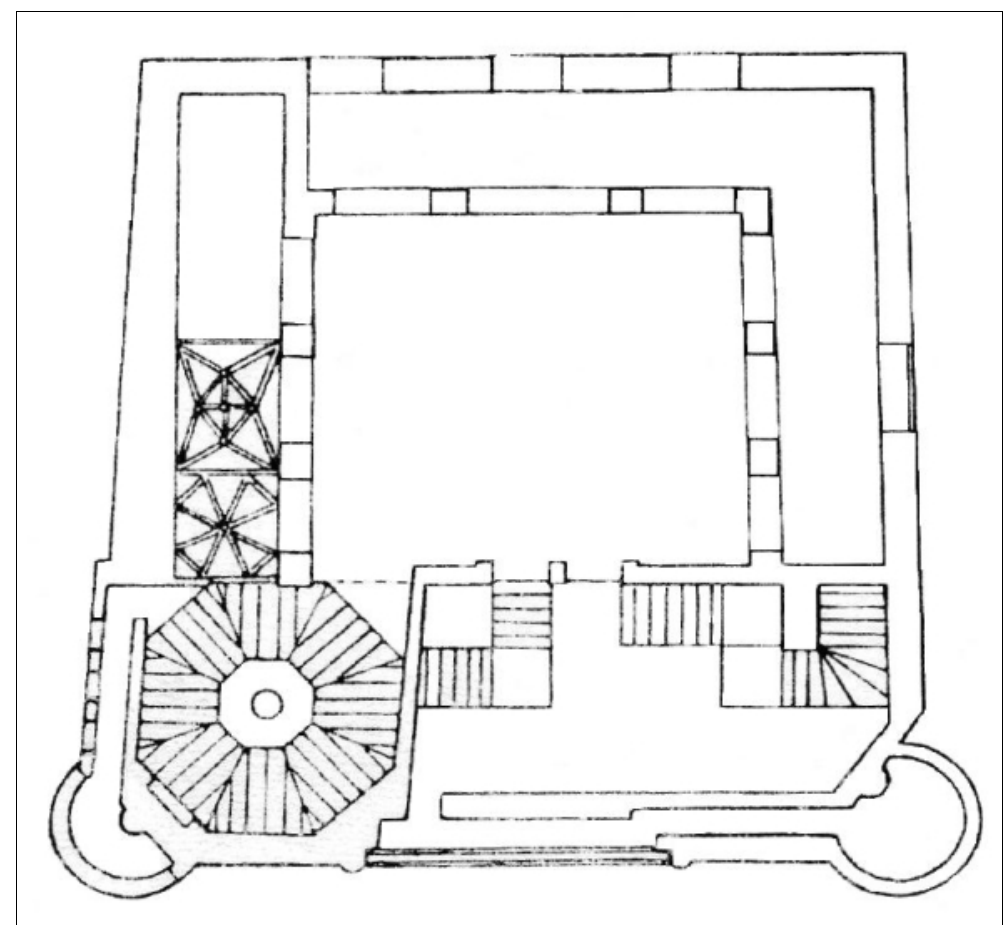

- Lám. 2. Esquema de la primera planta del Arco de Santa María (J. Rivera Blanco, Historia del Arte en Castilla y León. Renacimiento y Clasicismo, tomo V, Valladolid, 1994, p. 42).

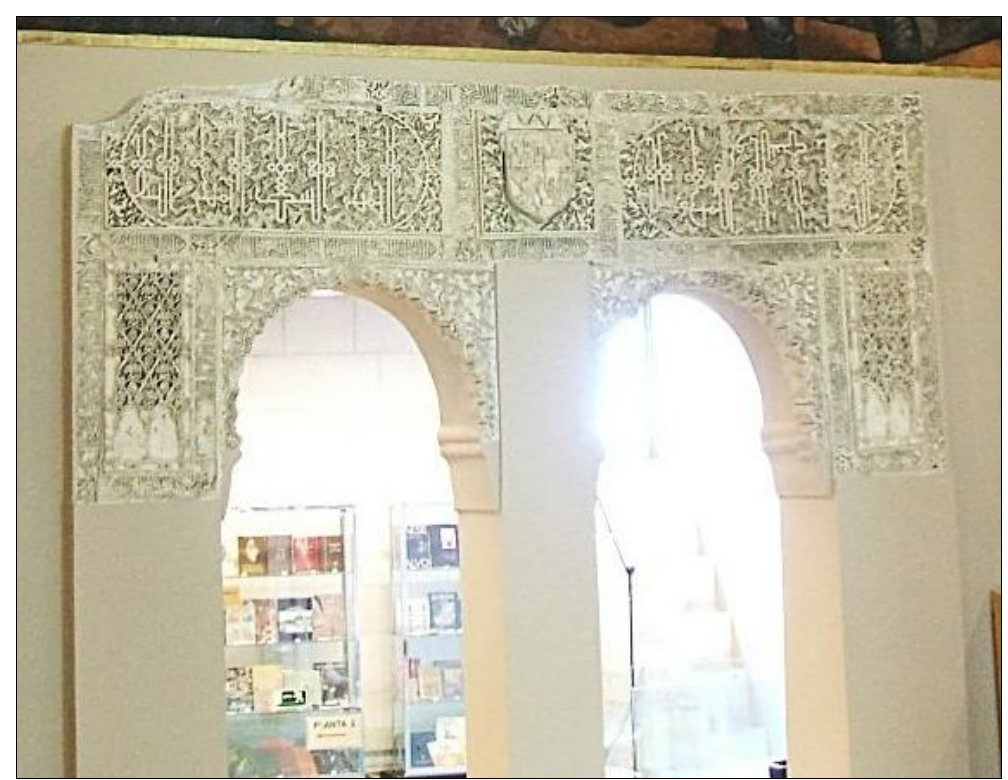

- Lám. 3. Arcos con decoración de yesería que comunicaban las salas primera y segunda del museo. 


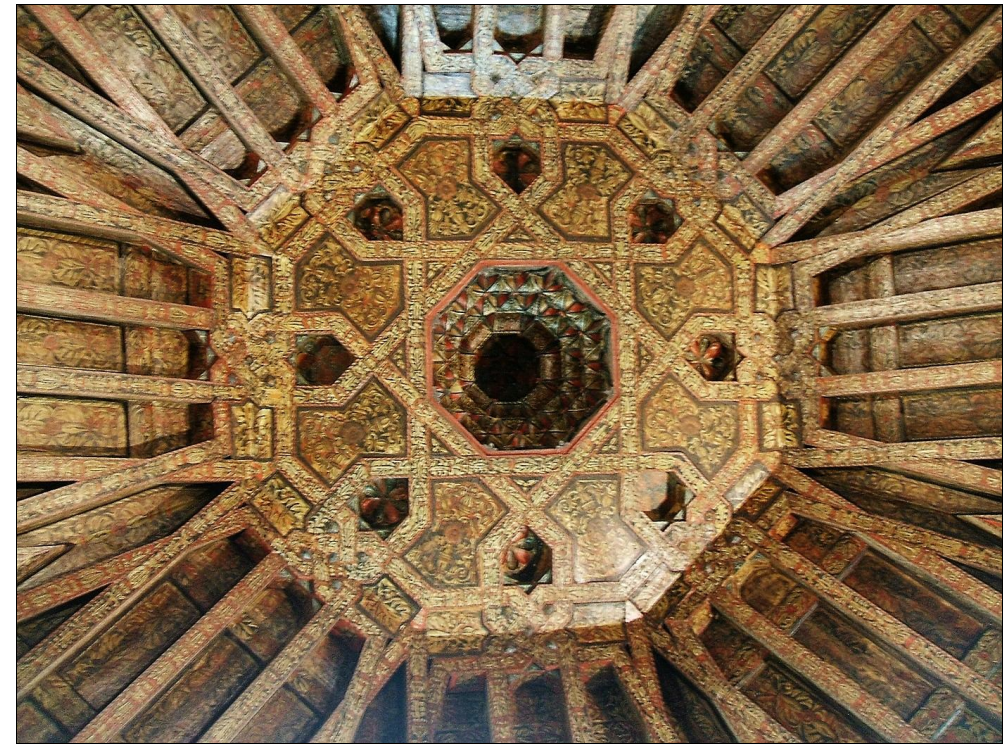

- Lám. 4. Cubierta de artesonado de la sala principal del museo, en otro tiempo sala de reunión del consejo municipal.

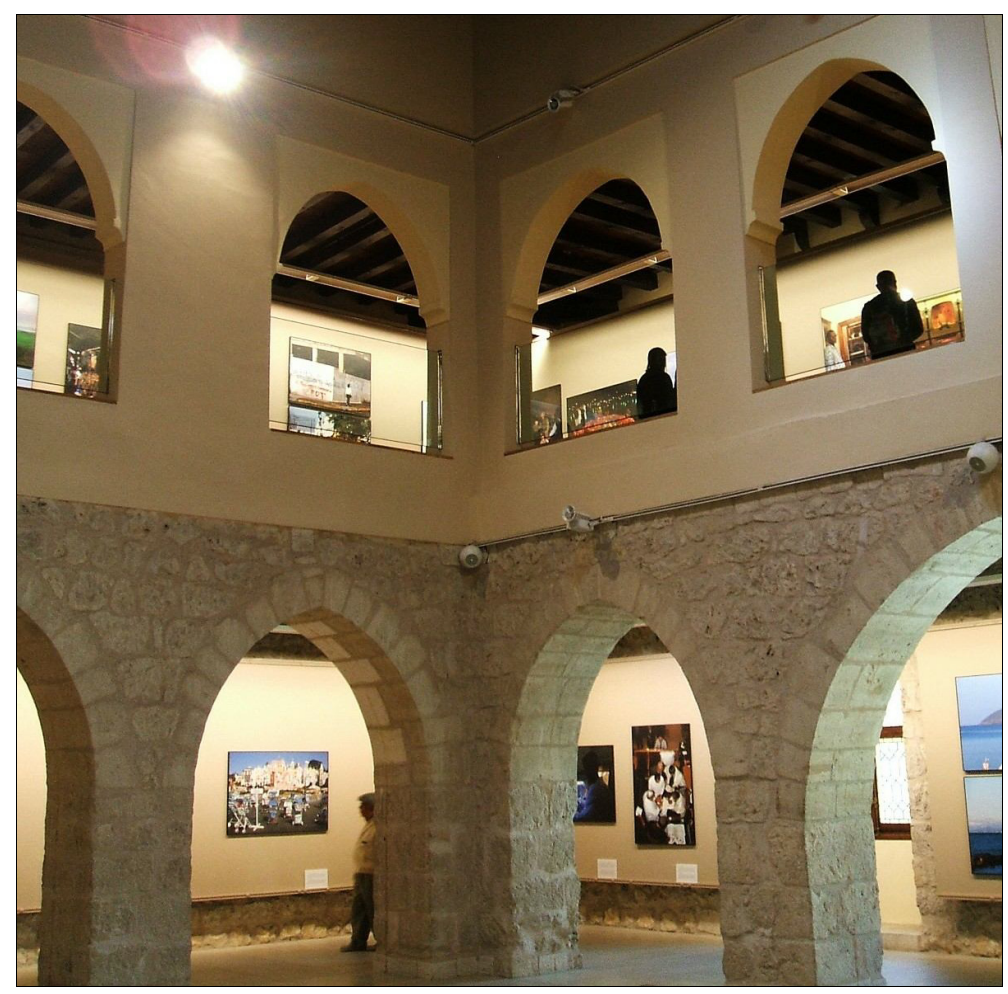

- Lám. 5. Vista de las galerías desde la sala central del arco, correspondiente a la sala segunda del museo. 